\title{
Rosai Dorfman Disease -A Rare Presentation: Case Report
}

\author{
Authors \\ Lionel Rohit Mathew ${ }^{1}$, Prema Devi ${ }^{2}$, C.S Vijayalakshmi ${ }^{3}$, Ezhilvizhi Alavandar ${ }^{4}$ \\ 1,2,3,4 Department of Pathology, Sri Muthukumaran Medical College Hospital\& \\ Research Institute, Chikkarayapuram, Mangadu,Chennai-600069 \\ Email: 1yamahalion@gmail.com,2premadevie@gmail.com,3vijaylux2003@gmail.com, \\ ${ }^{4}$ nsalavandar@gmail.com \\ Corresponding Author \\ Lionel Rohit Mathew \\ Department of Pathology, Sri Muthukumaran Medical College Hospital\& \\ Research Institute, Chikkarayapuram, Mangadu,Chennai-600069 \\ Email: yamahalion@gmail.com
}

\section{ABSTRACT}

We present a case of Rosai Dorfman Disease of bilateral inguinal nodes, for its unusual presentation. We diagnosed it based on the characteristic cytological and histomorphological findings and confirmed it using Immunohistochemistry.

Keywords-Rosai Dorfman Disease, Sinus Histiocytosis with Massive Lymphadenopathy, Emperipolesis.

\section{INTRODUCTION}

Sinus Histiocytosis with Massive Lymphadenopathy (Rosai Dorfman Disease) is an indolent histiocytic disorder that usually presents in young blacks, with massive painless bilateral cervical lymphadenopathy along with fever, leukocytosis and polyclonal hypergammaglobulinemia. It can be diagnosed based on its characteristic histomorphology. The disease is selflimiting. Death is very rare and results mainly from immunological abnormalities or infections ${ }^{1}$.

\section{CASE REPORT}

A previously healthy 37-year-old female presented with a history of pain in lower abdomen for 6 months, with loss of weight and intermittent fever. Physical examination revealed pallor. She had swellings in both inguinal regions. The swelling on the left inguinal region $(6 \mathrm{~cm})$ was larger than those on the right $(3 \mathrm{~cm}$ and $2 \mathrm{~cm})$.

Hematological investigations showed microcytic hypochromic anaemia (Haemoglobin - $6.9 \mathrm{~g} \%$ ) and elevated Erythrocyte Sedimentation Rate (42 $\mathrm{mm} / \mathrm{hr}$ ).

A computerized tomography scan revealed welldefined homogeneously enhancing oval isodense soft tissue density lesions in both iliac fossae in close relationship to the round ligaments (Fig. 1). A differential diagnosis of lymph nodal mass/round ligament leiomyoma/neurogenic mass was suggested and Fine Needle Aspiration was advised. The Aspiration Cytology revealed plenty of histiocytes showing emperipolesis (Fig. 2). An incisional biopsy was subsequently performed, the 


\section{JMSCR Vol||04||Issue||05||Page 10577-10580||May}

tissue of which revealed clusters and sheets of mononucleate and binucleate plasma cells (Fig. 3). Hence, the patient was advised to have a serum electrophoresis to rule out plasma cell dyscrasias. Serum Electrophoresis revealed elevated gamma globulins.

The patient was given blood transfusion and then, surgical excision of 3 inguinal masses ( 1 from left and 2 from right, Fig. 4-5). Grossly, they had a firm, tan-white fleshy cut surface. After extensive sampling, histomorphology showed lymph node with effacement of architecture. There were large areas of fibrosis accompanied by sheets of plasma cells. The sinuses were expanded and filled with histiocytes exhibiting emperipolesis by intact lymphocytes (Fig. 6-7). A diagnosis of SHML was made.

In order to confirm the diagnosis, immunohistochemistry was done. The histiocytes were positive for histiocytic markers S100 and CD68 and negative for CD1a, a marker for Langerhan cells (Fig. 8-10).

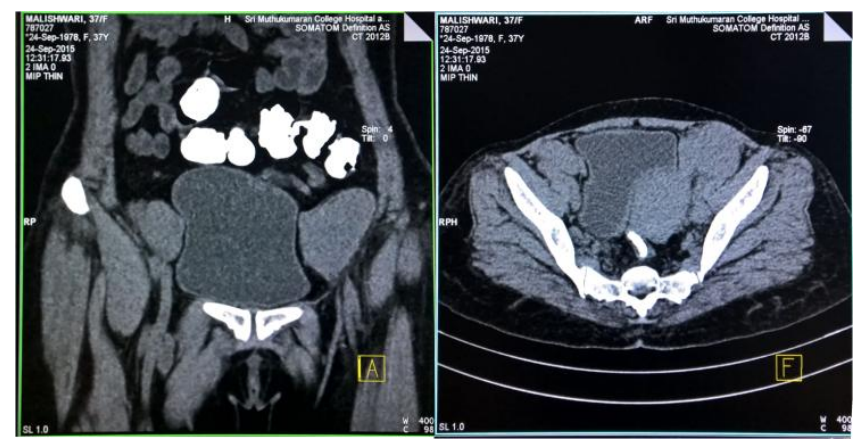

Fig. 1 Computerized Tomography scan showing bilateral inguinal swellings.

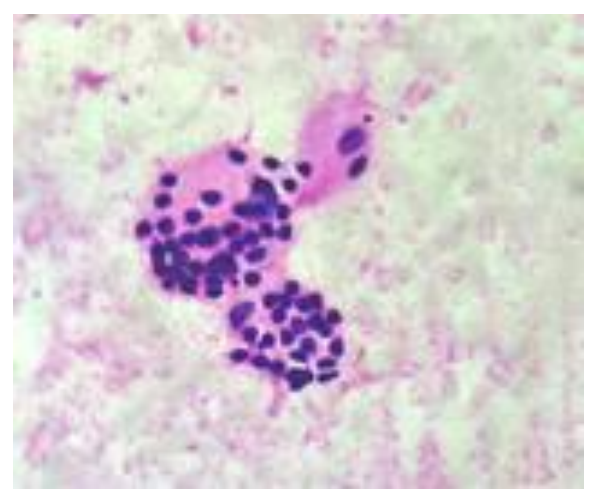

Fig. 2 Fine Needle Aspiration cytology from left inguinal swelling showing histiocytes containing engulfed lymphocytes.

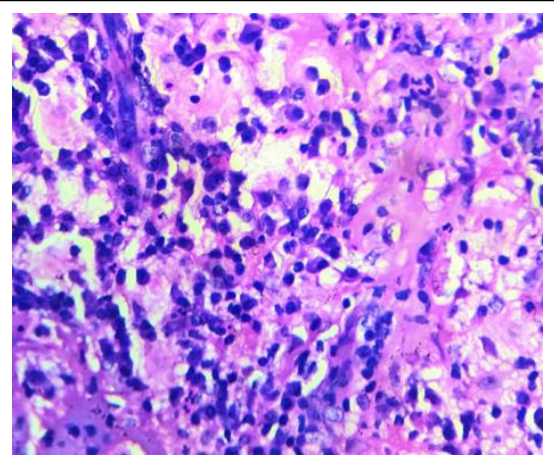

Fig. 3 Incisional Biopsy from left inguinal swelling showing plasmacytosis.

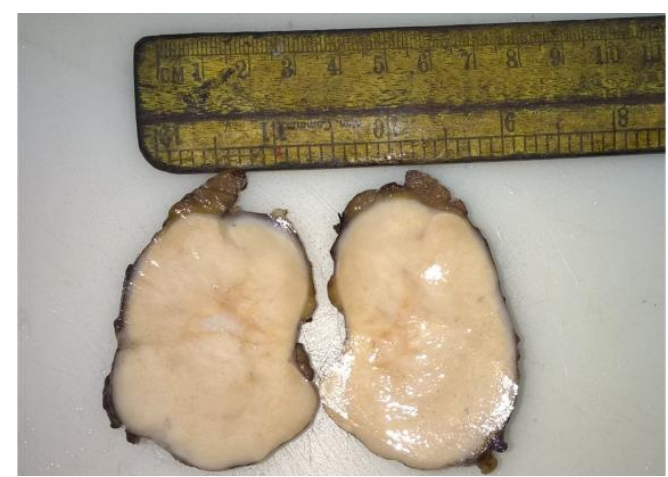

Fig. 4 Left inguinal node swelling.

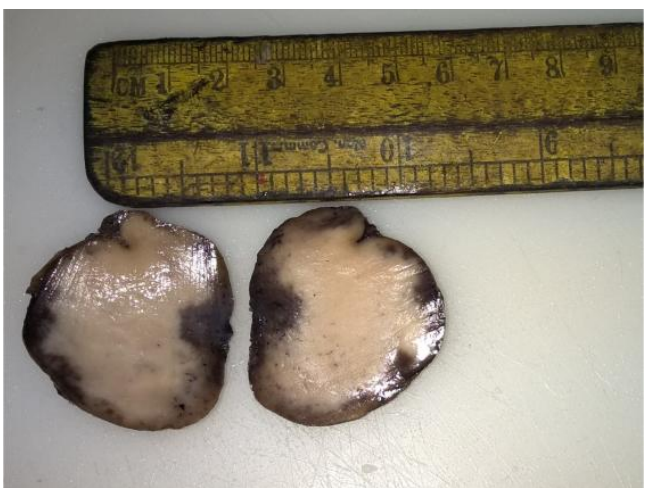

Fig. 5 Right inguinal node swelling.

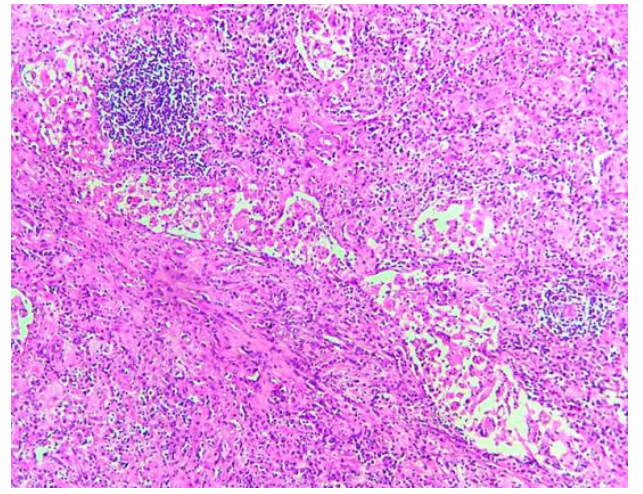

Fig. 6 Low-power view of lymph node showing fibrosis and sinus expansion. 


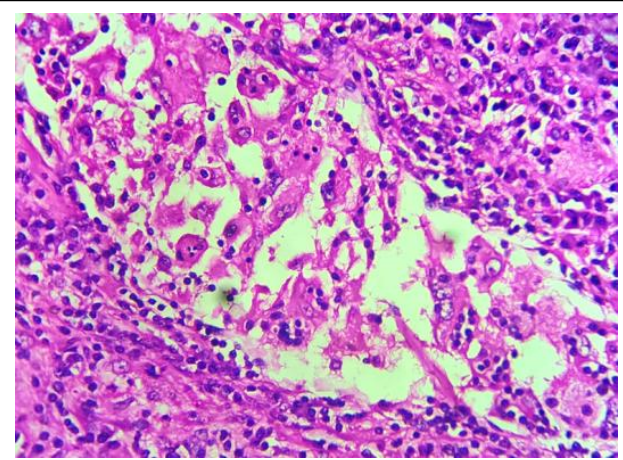

Fig. 7 High-power view of lymph node sinuses showing histiocytes with engulfed lymphocytes.

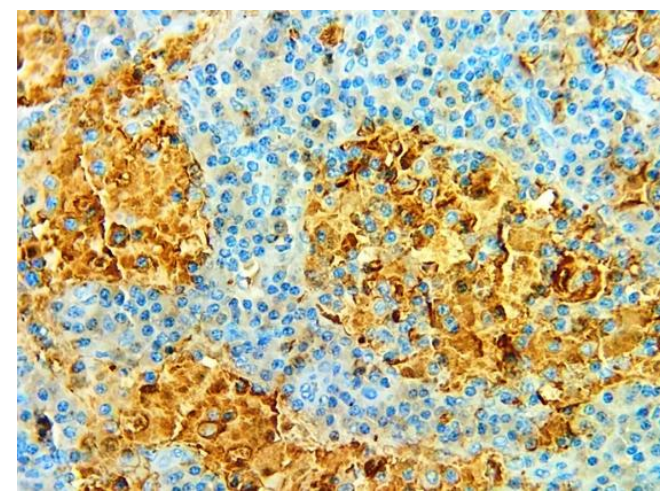

Fig. 8 Histiocytes positive for S100.

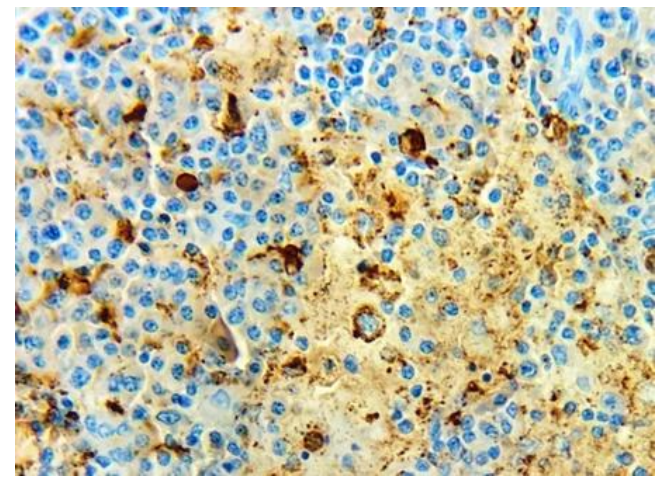

Fig. 9 Histiocytes positive for CD68

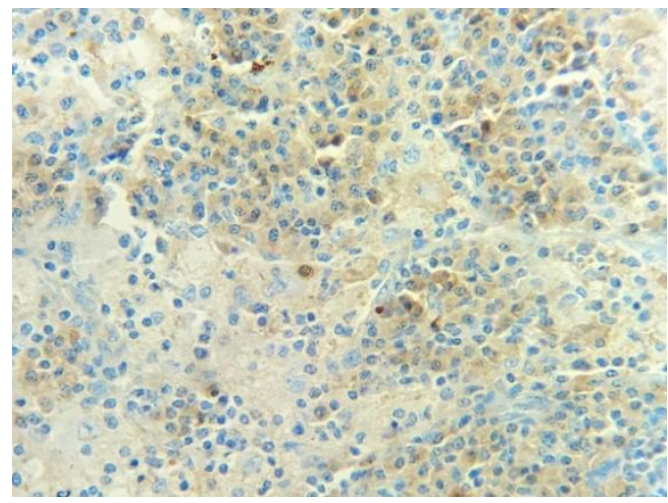

Fig. 10 Histiocytes negative for CD1a.

\section{DISCUSSION}

SHML, though reported in a wide age range, from newborn to 74, most commonly presents as cervical lymphadenopathy in children ${ }^{[2]}$. Extranodal SHML is common in the head and neck region, but is also common in skin of females in the third and fourth decade ${ }^{[3]}$. Here we observe a female in the $4^{\text {th }}$ decade of life, presenting with bilateral inguinal lymphadenopathy, which is very rare. Fever presented as a prodromal symptom. Hypergammaglobulinemia was present, which explains the raised erythrocyte sedimentation rate.

On cytological and histopathological examination, the phenomenon of emperipolesis was observed, which is a hallmark finding in SHML [4] Emperipolesis has also been observed in megakaryocytes and tumour cells in haematolymphoid malignancies and in nonhaematolymphoid malignancies ${ }^{\text {[5] }}$. Immunohistochemistry served to confirm the histiocytic nature of the cells and to rule out Langerhan Cell Histiocytosis ${ }^{[6],[7]}$.

\section{ACKNOWLEDGEMENTS}

We would like to thank the dean of Sri Muthukumaran Medical College Hospital and Research Institute and Dr. Sivaprakasam and his team of surgeons for operating on the patient. We also thank Dr. V. S. Mallikarjuna of S. M. Surgipath lab for Immunohistochemical studies.

\section{REFERENCES}

1. Foucar, E., Rosai, J. and Dorfman, R. F. (1984), Sinus histiocytosis with massive lymphadenopathy. An analysis of 14 deaths occurring in a patient registry. Cancer, 54: 1834-1840.

2. Harry L. Ioachim, L. Jeffrey Medeiros. Sinus Histiocytosis with Massive Lymphadenopathy. Ioachim's Lymph Node Pathology, $4^{\text {th }}$ edn. 2009 by Lippincott Williams \& Wilkins.

3. LeBoit P.E., Burg G., Weedon D, Sarasain A. (Eds.): World Health Organization Classification of Tumours. Pathology and Genetics of Skin Tumours. IARC Press: Lyon 2006. 
4. Patel, K. D., Rege, J. D. and Naik, L. P. (1996), Fine-needle aspiration cytology of sinus histiocytosis with massive lymphadenopathy: A case report. Diagn. Cytopathol., 15: 221-223.

5. Varun Rastogi, Rachna Sharma, Satya Ranjan Misra, Lalita Yadav, Vandana Sharma, EMPERIPOLESIS - A REVIEW.Journal of Clinical and Diagnostic Research [serial online] 2014 Dec[cited:2016 Apr 5] 12 ZM01 - ZM02

6. Eisen RN, Buckley PJ and Rosai J, Immunophenotypic Characterization of Sinus Histiocytosis with Massive Lymphadenopathy (Rosai-Dorfman disease), Semin Diagn Pathol. 1990 Feb; 7(1):74-82.

7. Middel, Hemmerlein, Fayyazi, Kaboth and Radzun (1999), Sinus Histiocytosis With Massive Lymphadenopathy: Evidence For Its Relationship To Macrophages And For A Cytokine-Related Disorder. Histopathology, 35: 525-53. 